\title{
СКВОЗНЫЕ ЦИФРОВЫЕ ТЕХНОЛОГИИ В ИННОВАЦИОННОМ РАЗВИТИИ РОССИИ
}

\section{ACROSS DIGITAL TECHNOLOGIES IN THE INNOVATIVE DEVELOPMENT OF RUSSIA}

\section{A. Shcherbakova}

Summary. In the article, the author examines various aspects of innovation and digital economies from the perspective of establishing the relationship between them. Diametrically different positions on this issue are considered - supporters of the activation of innovation based on digital technologies, including end-to-end, as well as experts who believe that digital technologies will only distribute the positions of the economies of countries on the world stage. The results of the world's leading ratings of digital and innovative economies of the countries of the world are displayed, the dynamics of changes in Russia's positions relative to other states is studied. The analysis of innovative activity of IT organizations and prospects of development of end-to-end digital technologies is presented. It is revealed that in the conditions of decreasing innovation activity of Russian IT companies, there is an increase in the efficiency of their innovation activities. The author has determined that end-to-end digital technologies are inherently innovative, therefore they have a direct impact on the activation of innovative development of the Russian economy.

Keywords: across digital technologies, innovative economy, digital economy, scientific and technological development, country rating.

\author{
Щербакова Анна Александровна \\ К.э.н., дочент, ФГБОУ ВО «Вологодский \\ государственный университет» \\ annascherbakova@mail.ru
}

Аннотация. В статье автором исследуются различные аспекты инновационной и цифровой экономик с позиции установления взаимосвязи между ними. Рассмотрены диаметрально разные позиции по этому вопросу сторонников активизации инновационной деятельности на основе цифровых технологий, в том числе и сквозных, а также экспертов, которые считают, что цифровые технологии только распределят позиции экономик стран на мировой арене. Отображены результаты ведущих мировых рейтингов цифровой и инновационной экономик стран мира, исследована динамика изменения позиций России относительно других государств. Представлен анализ инновационной деятельности ИТ-организаций и перспективы развития сквозных цифровых технологий. Выявлено, что в условиях снижения инновационной активности российских ИТ-компаний наблюдается повышение эффективности их инновационной деятельности. Автором определено, что сквозные цифровые технологии по своей сути являются инновационными, поэтому они оказывают непосредственное влияние на активизацию инновационного развития российской экономики.

Ключевые слова: сквозные цифровые технологии, инновационная экономика, цифровая экономика, научно-техническое развитие, рейтинг стран.

на более высокоуровневое научно-техническое развитие.

В целом эта гипотеза интересна в научном плане, поэтому в статье ставится цель - исследовать различные аспекты инновационной и цифровой экономик и установить между ними возможные связи.

Группа исследователей [11], изучив отечественный и зарубежный опыт по этому вопросу, отмечает, что цифровизация экономики является неотъемлемой частью современного инновационного развития. Они указывают на то, что цифровизации и цифровой трансформации экономики сегодня сопутствуют различные инновационные процессы.

Как отмечает Захаров Д.В. [4]: «Сегодня переход на цифровую экономику один из главных приоритетов развития России, ведь именно уровень цифровиза- 
Таблица 1. Тренды развития сквозных цифровых технологий НП «Цифровая экономика»

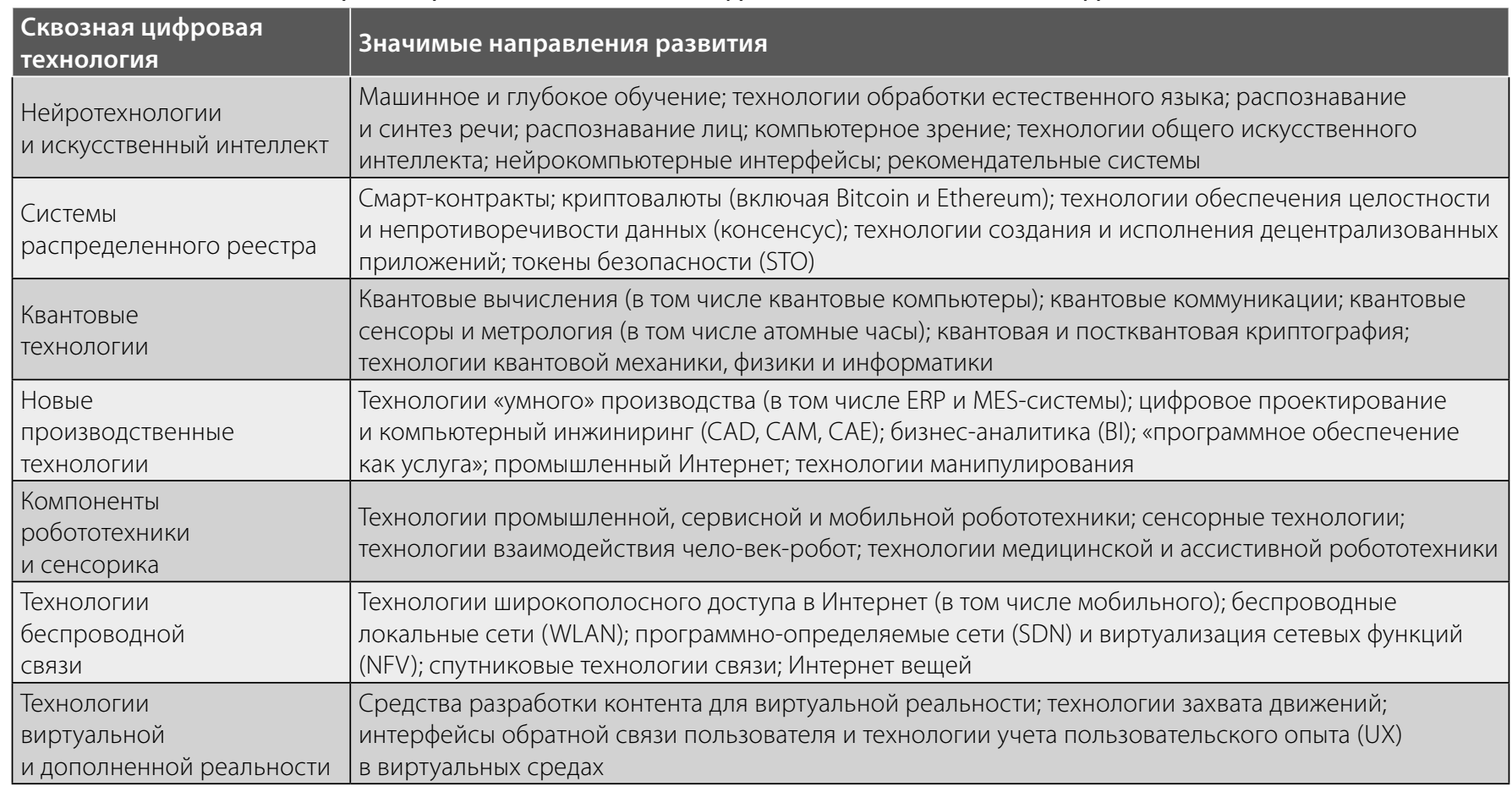

ции будет показывать конкурентоспособность страны в новом технологическом укладе. Поэтому, для выхода нашей страны на новый уровень развития экономики, социальных отраслей нужны собственные научные решения и передовые разработки. Необходимо развитие страны в тех направлениях, где накапливается мощный технологический потенциал будущего, а это цифровые, другие, так называемые сквозные технологии, которые сегодня определяют облик всех сфер жизни». Исследователь ссылается на сквозные цифровые технологии - передовые научно-технические отрасли, обеспечивающие создание высокотехнологичных продуктов и сервисов и наиболее сильно влияющие на развитие экономики, радикально меняющие ситуацию на существующих рынках и способствующие формированию новых рынков.

Понятие сквозные применено в связи с тем, что эти технологии не связаны с каким-то отдельным продуктом или сферой деятельности, а могут применяться во многих индустриях, отраслях и секторах экономики, например, в образовании, медицине, энергетике, строительстве, сельском хозяйстве, машиностроении и т.д. Сквозные технологии универсальны, используются не только в частном (коммерческом), но и в государственном секторе экономики.

В таблице 1 представлены тренды развития сквозных цифровых технологий согласно исследованиям На- циональный исследовательский университет «Высшая школа экономики» $[13,14]$.

Однако, члены [1, 8] Сретенского клуба им. С.П. Курдюмова скептически относятся к утверждению, что расширенное внедрение цифровых технологий приведет к экономическому росту. Появление и внедрение инноваций может приводить к серьезным положительным эффектам для экономики: повышение производительности труда; повышение капитализации; улучшение качества жизни; формирование новых рынков; повышение эффективности использования ресурсов (активов, капитала, компетенций); повышение конкурентоспособности; повышение безопасности. Но, как считают эксперты, в период развития процесса глобализации все указанные эффекты приводили к тому, что страны, составляющие ядро нового технологического уклада, получали значительные преимущества на международных рынках, что приводило к очередному перераспределению. Если рассматривать это с позиции отдельной страны, то это можно интерпретировать как экономический рост, обеспеченный внедрением новых технологий. Но с позиции мировой экономики происходит «дополнительная» капитализация коммерциализируемых новых технологий (за минусом капитализации вытесненной технологии). По их мнению, цифровая экономика не способна возродить экстенсивную модель капиталистического развития, если только она не сможет снова увеличить потенциал продаж. По этому вопросу эксперты утверждают, что 


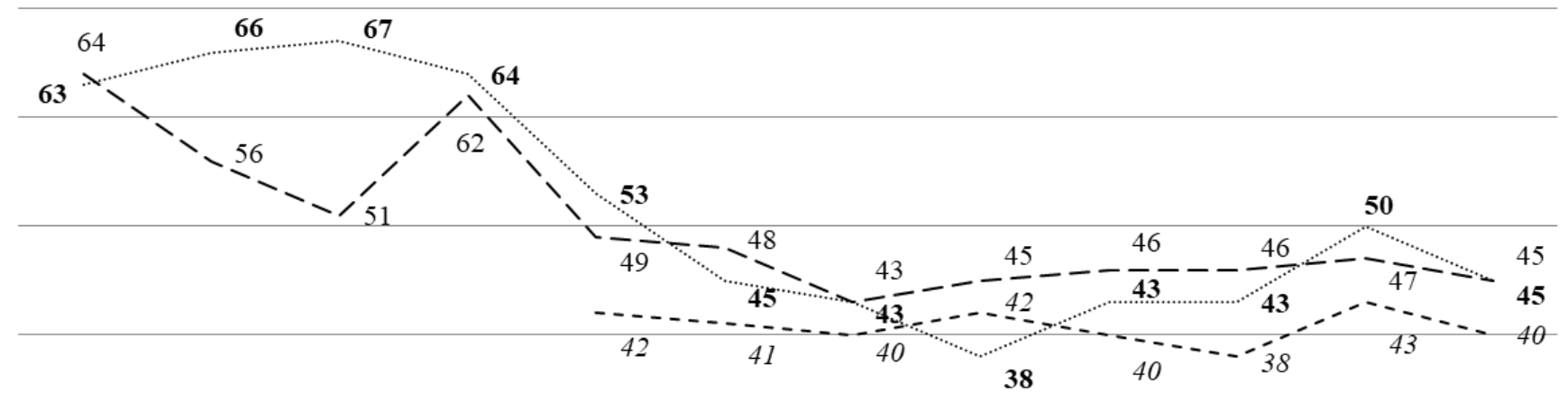

2010 г. 2011 г. 2012 г. 2013 г. 2014 г. 2015 г. 2016 г. 2017 г. 2018 г. 2019 г. 2020 г. 2021 г.

............. Индекс глобальной конкурентоспособности (Global Competitiveness Index, GCI)

- - - Глобальный индекс инноваций (Global Innovation Index)

- - - - Международный индекс цифровой конкурентоспособности (World Digital Competitiveness Index)

Рис. 1. Динамика изменения позиции России в мировых рейтингах

развитие цифровой экономики не является спасением экономики ни для России, ни для мира в целом. Сегодня для каждой отдельной страны это необходимая данность, которая позволит обеспечить конкурентоспособность, пересмотреть соотношение долей в мировой экономике и сохранить суверенитет.

Рассмотрев две диаметрально разных позиции, обратимся к ведущим мировым рейтингам цифровой и инновационной экономики (рисунок 1).

Глобальный индекс инноваций [2] Всемирной организации интеллектуальной собственности отражает основные тренды в области инноваций на основе набора из 81 показателя, характеризующих три аспекта инновационного процесса: а) инвестиции в науку и инновации, б) технологический прогресс, в) социально-экономическое воздействие. Рейтинг составляется для инновационных экосистем 132 экономик. В 2021 году наиболее инновационной экономикой является Швейцария, а за ней следуют Швеция, США, Великобритания и Республика Корея. С 2010 года Россия значительно улучшила свои позиции в рейтинге поднявшись с 63 на 45 место к 2021 году.

В Международном индексе цифровой конкурентоспособности [9], опубликованном швейцарской бизнес-школой IMD, Россия улучшила свои позиции по сравнению с прошлым годом и заняла 40 место (из 63 исследованных экономик). Рейтинг разрабатывается по 50 показателям в категориях: а) знания, б) технологии, в) будущая готовность. Лидерами рейтинга стали: США, Сингапур, Швеция.

Индекс глобальной конкурентоспособности [5] экономик оценивает принимаемые государствами меры по созданию конкурентной среды и благоприятных условий для ведения бизнеса в 64 странах мира по направлениям: а) макроэкономические показатели; б) качество государственного регулирования; в) эффективность бизнеса; г) социальная и транспортная инфраструктура. Россия поднялась в рейтинге с 50 на 45 пози- 

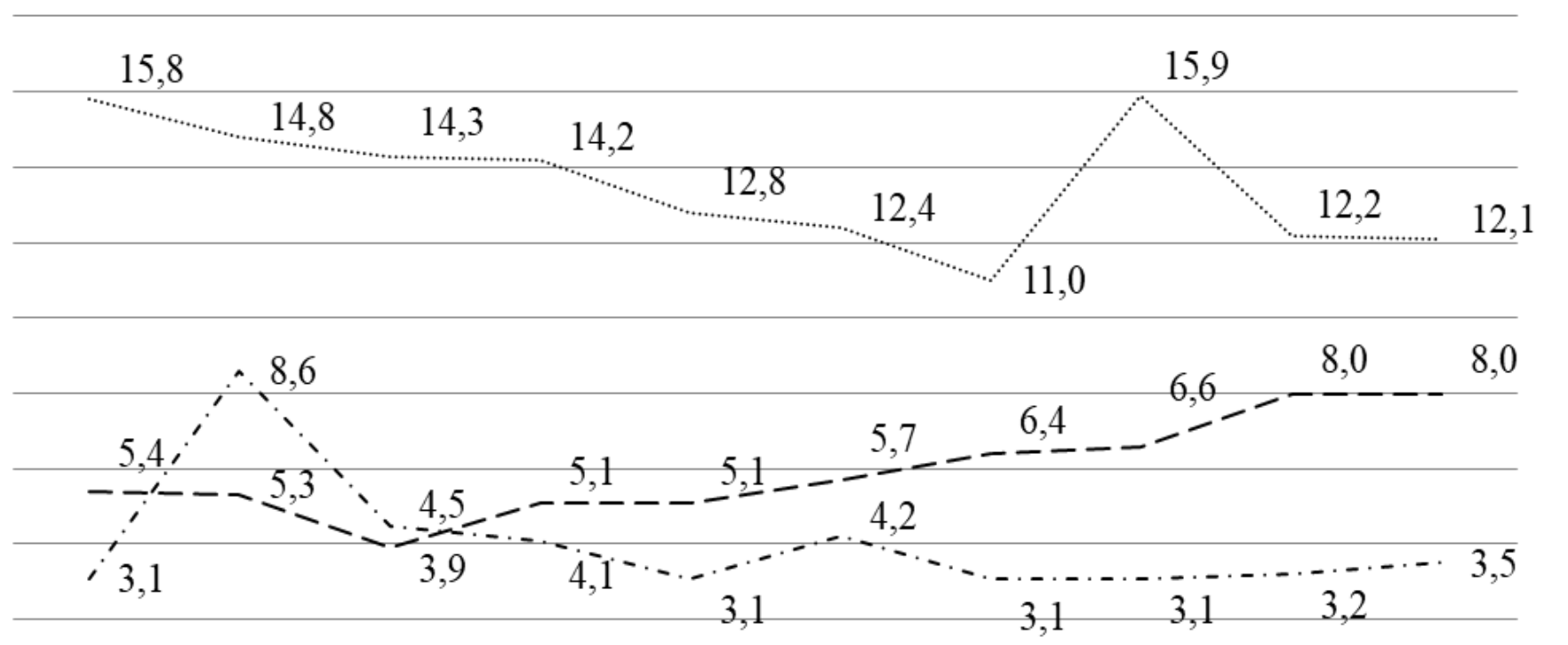

2010 г. 2011 г. 2012 г. 2013 г. 2014 г. 2015 г. 2016 г. 2017 г. 2018 г. 2019 г. Уровень инновационной активности организаций

\section{- - - Удельный вес инновационных товаров, работ, услуг в общем объеме отгруженных товаров, выполненных работ, услуг \\ - - - - Удельный вес затрат на инновационную деятельность в общем объеме отгруженных товаров, выполненных работ, услуг}

Рис. 2. Показатели инновационной деятельности организаций сектора ИКТ [6]

цию. Главными вызовами для России эксперты считают: необходимость ускорения экономического роста, бедность и неравенство, убыль населения, вопросы цифровизации, слабый уровень развития транспортной инфраструктуры и логистики. В первой пятерке списка расположились Швейцария, Швеция, Дания, Нидерланды и Сингапур.

Анализ рейтингов показывает, что показатели инновационной экономики и цифровой экономики в них разработчиками не отделяются, а исследуются в комплексе. Самыми развитыми странами в этих сферах являются Швеция и Швейцария. Можно сделать вывод, что мировое экспертное сообщество рассматривает цифровизацию и цифровую трансформацию совместно с инновационным развитием.

Страны активно включаются в мировые процессы цифровой экономики. Так в 2006 году в рамках стратегии «Высокие технологии», предложенной правительством Большой коалиции (Германия), была разработа- на Концепция развития промышленности «Индустрия 4.0». Эта стратегия получила мировое признание из-за четкости формирования цели и взята на вооружение многими странами мира. Она описывает концепцию «умного производства» на основе промышленного интернета вещей, объединяет физическое производство и операции с интеллектуальными цифровыми технологиями, машинным обучением и большими данными. Цифровизация - один из необходимых элементов модели Индустрии 4.0 .

В 2016 году Япония представила миру свою программу социальных изменений «Общество 5.0» на основе цифровых технологий. И если «Индустрия 4.0» пропагандирует «умный бизнес», то «Общество 5.0» ставит целью создание «суперумного общества». Концепция предусматривает цифровизацию на всех уровнях японского общества и его цифровую трансформацию. При этом важное значение в концепции отводится Интернету вещей, искусственному интеллекту, виртуальной и дополненной реальности, большим данным и другим 
цифровым технологиям. Однако это не просто цифровизация жизнедеятельности людей. Все намного глобальнее - концепция раскрывает решение важнейших проблем человечества и устойчивого развития экономики и общества в целом (старение населения, стихийные бедствия, загрязнение окружающей среды и др.).

Перспективы развития сквозных цифровых технологий эксперты Высшей школы экономики прогнозируют по следующим направлениям $[9,10]$ :

1. Геоинформационные и навигационные технологии (пространственные данные) - программно-технические средства обработки и передачи информации, позволяющие реализовать функциональные возможности геоинформационной системы.

2. Технологии фотоники - множество информационных, коммуникационных, производственных, энергетических и других технологий, базирующихся на эффективной передаче энергии и/или информации потоком одинаковых или почти одинаковых фотонов.

3. Технологии вычислений:

- облачных (технологии распределенной обработки данных, в которых компьютерные ресурсы и мощности предоставляются пользователю как Интернет-сервис);

- туманных (технологии, обеспечивающие доступ к масштабируемым вычислительным ресурсам, распределенным между конечными устройствами и облачными или дата-центрами);

- граничных (технологии обработки и хранения данных на конечном устройстве, обеспечивающие очень низкую (практически нулевую) задержку передачи данных за счет отсутствия необходимости передачи информации на большие расстояния от центров обработки данных до конечных устройств);

- росистых (технологии, основанные на концепции микросервисов, которые предоставляются устройствами конечного пользователя без помощи централизованных облачных сервисов):

4. Кибербиологические системы (в том числе нейротехнологии) - системы, обеспечивающие взаимодействие между мозгом человека и периферийными электронными устройствами.

5. Технологии аутентификации и идентификации (в том числе биометрические технологии) - тех- нологии проверки подлинности пользователя путем измерения физиологических параметров и характеристик человека, особенностей его поведения.

6. Аддитивные технологии (3D- и 4D-печать) технологии послойного создания трехмерных объектов на основе их цифровых моделей, позволяющие изготавливать изделия сложных геометрических форм и профилей.

7. Суперкомпьютерные и грид-технологии - технологии, обеспечивающие высокопроизводительные вычисления за счет использования принципов параллельной и распределенной (грид) обработки данных и высокой пропускной способности.

Далее выполним анализ основных показателей инновационной деятельности организаций сектора информационно-коммуникационных технологий (ИКТ) (рисунок 2).

Согласно данным McKinsey, цифровая экономика в России пока составляет лишь 4\% от ВВП, в то время как в США - около 10\%. Неблагоприятной тенденцией является то, что уровень инновационной активности за 2010-2019 годы российских ИТ-компаний снизился на 23,4\%. В то же время удельный вес инновационных товаров, работ и услуг в общем объеме отгруженных товаров, выполненных работ и услуг существенно увеличился - на 48,2\%. При этом наблюдается небольшое увеличение доли затрат на инновационную деятельность - на 12,9\%. То есть на фоне снижения инновационной активности ИТ-компаний России наблюдается повышение эффективности их инновационной деятельности.

Резюмируя, определим цифровую экономику как систему партнерских отношений и взаимовыгодного сотрудничества государства, бизнеса и общества, функционирующую в глобальном информационном пространстве и базирующуюся на внедрении и использовании цифровых технологий, что приводит к активизации инновационных процессов и повышению эффективности социально-экономического развития. Сквозные цифровые технологии по своей сути являются инновационными, поэтому они оказывают непосредственное влияние на активизацию инновационного развития российской экономики.

\section{ЛИТЕРАТУРА}

1. Введение в «Цифровую» экономику: методическое пособие к онлайн курсу / А.В. Кешелава В.Г. Буданов, В.Ю. Румянцев [и др.]; под общей редакцией А.В. Кешелава; главный «цифровой» консультант И.А. Зимненко.— Москва: ВНИИГеосистем, 2017. — 28 с.

2. Глобальный индекс инноваций._ URL: https://www.wipo.int/publications/ru/series/index.jsp?id=129 (дата обращения 16.12.2021). 
3. Денисенко, И.А. Функционирование и развитие предпринимательства в условиях цифровой экономики / И.А. Денисенко. - Текст: электронный // Сервис в России и за рубежом. — 2018. — № 4 (82).—URL: https://cyberleninka.ru/article/n/funktsionirovanie-i-razvitie-predprinimatelstva-v-usloviyahtsifrovoy-ekonomiki (дата обращения: 05.11.2021).

4. Захаров Д.В. Цифровизация экономики: проблемы и перспективы // Развитие науки, национальной инновационной системы и технологий: сборник научных трудов по материалам Международной научно-практической конференции 13 мая 2020 г.: Белгород: 000 Агентство перспективных научных исследований (АПНИ), 2020. С. 102-107.—URL: https://apni.ru/article/679-tsifrovizatsiya-ekonomiki-problemi-i-perspekt (дата 0бращения: 16.12.2021).

5. Индекс глобальной конкурентоспособности.—URL: http://reports.weforum.org/ (дата обращения 16.12.2021).

6. Индикаторы цифровой экономики: 2021: статистический сборник / Г.И. Абдрахманова, К.О. Вишневский, Л.М. Гохберг и др.; Нац. исслед. ун-т «Высшая школа экономики».—- М.: НИУ ВШЭ, 2021. - 380 с.

7. Интеллектуальная экономика: как искусственный интеллект трансформирует отрасли и общество.— - Текст: электронный.—URL: http://info.microsoft. com/rs/157-GQE-382/images/RU-RU-CNTNT-Whitepaper-Digital-Transformation-with-Al-Intelligent-Economies.pdf (дата 0бращения: 05.11.2021).

8. Кешелава, А.В. Предмет цифровой экономики и роль цифровых инструментов / А.В. Кешелава, И.Л. Хает.— Текст: электронный.— URL: http:// digital-economy.ru/images/easyblog_articles/485/DE-2019-02-13.pdf (дата обращения: 10.11.2021).

9. Международный индекс цифровой конкурентоспособности. — URL: www.imd.org/wcc/ (дата обращения 16.12.2021).

10. Полянская, О.А. Положительные и отрицательные тенденции развития цифровой экономики в России / О.А. Полянская, В.В. Беспалова, В.Н. Татаренко. - Текст: электронный // Петербургский экономический журнал. — 2018. — № 3.— URL: https://cyberleninka.ru/article/n/polozhitelnye-iotritsatelnye-tendentsii-razvitiya-tsifrovoy-ekonomiki-v-rossii (дата обращения: 12.11.2021).

11. Родионова И.А., Кокуйцева Т.В., Харламов М.М. Особенности развития цифровизации в Российской Федерации и в развитых странах мира: анализ позиций в международных рейтингах // Экономические отношения. - 2020.— Том 10. — № 2. — С. 381-394.

12. Тапскотт, Д. Электронно-цифровое общество: плюсы и минусы эпохи сетевого интеллекта / Д. Тапскотт; перевод с английского И. Дубинского; под редакцией С. Писарева.—Киев; Москва: ITN Пресс: Рефлбук, 1999. —403 с.

13. Цифровая трансформация отраслей: стартовые условия и приоритеты: доклад к XXII Апрельской международной научной конференции по проблемам развития экономики и общества, (Москва, 13-30 апр. 2021 г.) / Г.И. Абдрахманова, К.Б. Быховский, Н.Н. Веселитская, К.0. Вишневский, Л.М. Гохберг и др.; руководитель авторского коллектива П.Б. Рудник; научные редакторы: Л.М. Гохберг, П.Б. Рудник, К.О. Вишневский, Т.С. Зинина; Национальный исследовательский университет «Высшая школа экономики».—- Москва: Издательский дом Высшей школы экономики, 2021. — 239 с.

14. Цифровые технологии в российской экономике / К.О. Вишневский, Л.М. Гохберг, В.В. Дементьев и др.; под редакцией Л.М. Гохберга; Национальный исследовательский университет «Высшая школа экономики».—- Москва: НИУ ВШЭ, 2021. - 116 с.

(c) Щербакова Анна Александровна ( annascherbakova@mail.ru ).

Журнал «Современная наука: актуальные проблемы теории и практики» 